\title{
Issues of Antibiotic Resistance in Aquaculture Industry and Its Way Forward
}

\author{
Nilav Aich ${ }^{1 *}$, Naznin Ahmed ${ }^{2}$ and Anirban Paul ${ }^{3}$ \\ ${ }^{1}$ Department of fisheries, Tripura, India \\ ${ }^{2}$ Department of Fisheries, Assam, India \\ ${ }^{3}$ ICAR-Central Institute of Freshwater Aquaculture, Kausalyaganga, \\ Bhubaneswar 751002, India \\ *Corresponding author
}

\begin{tabular}{|c|}
\hline Keywords \\
\hline $\begin{array}{l}\text { Alternative approach, } \\
\text { Antimicrobial resistance, } \\
\text { Bacteriophage therapy, } \\
\text { Immunostimulants, } \\
\text { Prebiotics, Probiotics, } \\
\text { Quorum sensing } \\
\text { inhibition, RNA } \\
\text { interference, Synbiotics, } \\
\text { Vaccine }\end{array}$ \\
\hline Article Info \\
\hline $\begin{array}{l}\text { Accepted: } \\
\text { 04 July } 2018 \\
\text { Available Online: } \\
\text { 10 August } 2018\end{array}$ \\
\hline
\end{tabular}

A B S T R A C T

Use of antibiotics as a therapeutic measure is the most used method for the treatment of infectious diseases including in fisheries and aquaculture. The successful use of any antibiotic in aquaculture is compromised due to the emergence of antimicrobial resistance in bacteria. Bacteria may be intrinsically resistant to different antimicrobial agents or they may acquire resistance through horizontal gene transfer. A number of biochemical and physiological mechanisms are responsible for the development of this resistance. Antimicrobial resistance developed in one ecological niche can spread to another ecological niche and finally can reach the human resulting in a number of treatment failures and high life threatening diseases. The unregulated use of antimicrobial agents has led to the development of antimicrobial resistant fish pathogens as well as other aquatic bacteria. The resistance has been observed in a number of bacterial species including Aeromonas hydrophila, A. salmonicida, Yersinia ruckeri, Edwardsiella tarda, E. ictaluri, Vibrio anguillarum, V. salmonicida, Photobacterium damselae. Multidrug-resistant strains of A. salmonicida and Vibrio harveyi have been reported from different parts of the country. The residues of antimicrobial agents also possess a threat to human health causing allergy, toxicity, alterations of the intestinal flora etc. Antibiotic residues represents potential health hazard and also affects the trade prospects. In this critical scenario different alternative approach can play a crucial role, such as Probiotics, prebiotics and synbiotics, immunostimulants, bacteriophage therapy, vaccine, RNA interference, quorum sensing inhibition etc. All this alternative measures can be used as prophylactic or control measure for fish disease management without hampering the environment. Vaccination is one of the most promising alternatives for the disease management which is being already in use in so many countries. There is every day increasing research in this field of antimicrobial alternatives measures and there are many success stories in the lab as well as in the field also. So days are coming when we can proudly say no to antibiotic use in aquaculture. 


\section{Introduction}

Exponential growth of the world population keeps on challenging the fish productivity to meet the protein requirement. There is huge sift of the fish culture practices from extensive to intensive. But to attain this intensification we have saddled lots of stress to the culture animal and environment which leads to devastating diseases. So to combat with these diseases we have used so many remedial measures and antibiotics are one of those. Different Antibiotics are the most widely used remedial measures against bacterial fish infections. Antibiotics are drugs of natural or synthetic origin that have the capacity to kill or to inhibit the growth of micro-organisms (Serrano, 2005). A therapeutic level of antibiotics is used for treatment, control, or prevention of animal diseases (Landers et al., 2012). Sub-therapeutic levels of antibiotics, such as penicillin or tetracycline, are provided to food animals in their feed in order to enhance their feed / weight efficiency ratios (Marshall and Levy 2011). In aquaculture, the antimicrobials are mainly administered either through medicated feed or adding antimicrobial agents directly to the pond water. Both the methods may result in heavy use of antimicrobial agents and provide a strong selective pressure in the aquatic animals, as well as in the exposed environments (Le and Munekage, 2004). Intensive use of antimicrobial agents in aquaculture has resulted in the emergence of reservoirs of antimicrobial-resistant bacteria in fish and other aquatic animals. From these reservoirs the resistant genes may reach human pathogens indirectly through horizontal gene transfer or the drug resistant pathogens may reach human directly from the aquatic environment (Heueret al., 2009). Because of the antibiotic resistance problem the bacterial diseases are becoming hard to control. So antibiotic resistance is a big concern, which stands true for whole animal kingdom as a whole as resistance can be easily transferred from one bacteria to another.

\section{Major classes of antibiotics}

There are several major classes of antibiotics based on their mechanism of action.

\section{Antibioticsthat inhibit cell wall synthesis}

Inhibition of cell wall synthesis is the most common bactericidal activity. The major group of antibiotics under this category is $\beta$ lactams. These antibiotics are so named because they have a common $\beta$-lactam ring structure (Murray et al., 2012). Examples are penicillins, cephalosphorins, cephamycins, carbapenems, monobactams, and $\beta$-lactamase inhibitors. $\beta$-lactam antibiotics act as bactericidal agents. Bacterial cell wall forms by chain of alternating $\mathrm{N}$-acetylglucosamine and $\mathrm{N}$-acetylmuramic residues. In the final step of cell wall synthesis transpeptidase catalysed cross-linking of polypeptidoglycan chain and cell wall form. Binding of $\beta$-lactams drugs to the bacterial transpeptidase cause hydrolysis of $\beta$-lactams bond thereby inhibiting the final transpepdation step of cell wall synthesis. Thus $\beta$-lactamsbind to specific penicillin binding proteins (PBPs) 1, 2 and 3 in the bacterial cell wall results in cell wall lysis, disruption of cell shape and inhibition of cell division respectively.Other antibiotics under this category are vancomycin, daptomycin and bacitracin.

\section{Antibioticsthat inhibit protein synthesis}

These antibacterial agents inhibit protein synthesis either by binding to 30s ribosomal subunit or 50s ribosomal subunit (Neu and gootz 1996, Murray et al., 2012). Aminoglycosides such as streptomycin, neomycin and kanamycin irreversibly bind to 30s ribosomal proteins (bactericidal). Tetracyclines such as tetracycline, 
doxycycline and minocycline also inhibit protein synthesis by reversibly binding to $30 \mathrm{~s}$ ribosomal subunits (bacteriostatic). They block tRNA binding to $30 \mathrm{~s}$ ribosome-mRNA complex. Chloramphenicols bind peptidyltransferase component of $50 \mathrm{~s}$ ribosome, blocking peptide elongation (bacteriostatic). Macrolides such as erythromycin, azithromycin and clarithromycin reversibly bind to the $23 \mathrm{~s}$ ribosomal RNA of the 50s ribosomal subunit, which blocks peptide elongation (bacteriostatic).Clindamycin binds to the 50s ribosome, blocks peptide elongation; Inhibits peptidyl transferase by interfering with binding of amino acid-acyl-tRNA complex.

Antibiotics that inhibit nucleic acid synthesis

Quinolonesinhibit DNA gyrases or topoisomerases required for supercoiling of DNA. Rifampicin binds to DNA-dependent RNA polymerase and inhibits the initiation of RNA synthesis (Neu and gootz, 1996).

\section{Antibiotics that inhibit metabolic pathways}

Sulfonamides and Dapsone compete with paminobenzoic acid (PABA) preventing synthesis of folic acid. Trimethoprim inhibits dihydrofolate reductase preventing synthesis of folic acid (Murray et al., 2012).

\section{Bacterial resistance mechanisms to antimicrobial agents}

Bacteria have found ways to overcome the growth-inhibitory properties of the antimicrobial agents and gain resistance towards that. Bacterial pathogens that are resistant to a single drug quite frequently become resistant to multiple antimicrobial agents and are considered potentially untreatable "superbugs" (Morris et al., 1998, Levy, 2005). The general mechanisms that are responsible for bacterial resistances to antimicrobial agents are (a) enzymatic inactivation of drugs (b) drug target modification(c) decreased membrane permeability and (d) active efflux of drugs (Kumar and Varela 2013). Bacteria which harbour these drug resistant mechanisms can survive, or even actively grow in the presence of a given antimicrobial agent.

\section{Enzymatic inactivation of drugs}

Bacteria have evolved several mechanisms of drug inactivation such as the enzymatic hydrolysis of antibiotics, group transfer and the redox process (Davies 1994). Certain bacteria produce the enzyme $\beta$-lactamases that hydrolyze the $\beta$-lactam ring of penicillins. $\beta$ lactamases such as TEM, SHV (sulphydril variable active site) can hydrolyze a broad range of extended spectrum cephalosporins, and these are collectively called extended spectrum $\beta$-lactamases, or ESBLs (Philippon et al., 1989). ESBLs hydrolyze a wide range of cephalosporins such as ceftriaxone, ceftazidime, cefotaxime and aztreonam, but do not hydrolyze cephalomycins and carbapenems (Bradford, 2001). Other hydrolysing enzymes are esterases and epoxidases which can hydrolyse the antibiotics macrolides and fosfomycin respectively.

Another mechanism of antibiotic inactivation is enzyme mediated structural alteration of the drug via transfer of a functional group such as an acyl, ribosyl, phosphoryl or thiol group (Wright, 2005). This results in change in structure of the antibiotics which make it unable to bind to the target. Redox process is a less common mechanism which involves flavin-dependent monoxygenase enzyme TetX. This enzyme transfers a single hydroxyl group to tetracycline and makes it less able to sequester $\mathrm{Mg}+$ ions which are critical for binding of tetracycline to its bacterial target (Yang et al., 2004). 


\section{Drug target modification}

Bacteria have developed various means to alter and modify the molecular targets of antimicrobial agents. Modification of the drug target makes the drug unable to bind to its specific site. For example; DNA gyrase is a target of the drug quinolone. Modification in DNA gyrase makes the drug unable to bind to its target (Fabrega et al., 2009). Other examples of drug targets are prokaryotic ribosome, a target for protein synthesis inhibitors; RNA polymerase, a target of rifampin (Spratt, 1994; Drapeau et al., 2010), penicillin binding protein (PCB), a target of $\beta$ lactam antibiotics (Neu and gootz 1996, Fisher et al., 2005).

\section{Decreased membrane permeability}

The drug molecules can penetrate the bacterial outer membrane either by diffusion through porins or by diffusion through the bilayer. Drug resistance in a bacterium may arise due to the inability of the drug to gain entry into the cell where the drug targets are located (Kumar and Schweizer, 2005). Bacteria having lipopolysaccharide (LPS) moieties show resistance to erythromycin, roxithromycin, clarithromycin and azithromycin in Gram-negative bacteria such as strains of Pseudomonas aeruginosa, $V$. cholerae and $S$. enterica, especially in immune-compromised patients (Strateva and Yordanov, 2009; Kitakoa et al., 2011; Monack, 2012). Another drug resistance mechanism is through reducing the number of porin channels which allow small molecular weight molecules, such as antimicrobial agents, to gain cellular entry (Pages et al., 2008).

\section{Active efflux of drugs}

Drug efflux pumps are located on the cytoplasmic or plasma membranes of bacteria and prevent drug accumulation inside the bacterial cells, thereby conferring resistance (Levy, 2002). There are two main categories of active efflux pump; called the primary active transporters which use the energy from hydrolysis of ATP to actively efflux drugs from cells (Higgins, 2007). The second category is called secondary active transporters that use an ion gradient for transportation of drugs across the membrane (Poolman and Konings, 1993; Kramer, 1994)

\section{Development and spread of antimicrobial resistance}

Development and spread of antimicrobial resistance due to the use of antimicrobial agents in both humans and animals has become a global public health concern (Heuer et al., 2009). Unregulated use and misuse of antimicrobials allows the less susceptible bacteria to survive and adapt to the low drug concentration and develop resistance (Levy, 1998). Antimicrobial resistance developed in one ecological niche can spread to another such as use of antimicrobials in aquaculture can lead to occurrence of antimicrobial resistance in human environment. This is because several antibiotics which are classified by World Health Organization (WHO) as critically important for the treatment of human disease are also used in aquaculture (Heuer et al., 2009). Bacteria may be intrinsically resistant to different antimicrobial agents. Intrinsic resistance refers to the existence of genes in bacterial genomes that could generate a resistance phenotype (Davies and Davies 2010). Bacteria can acquire resistant genes by various means and transfer it to a new bacterium with the help of mobile genetic elements, such as plasmids and transposable elements (Romero et al., 2012). Viruses can also transfer resistance genes occasionally by extracting genes from one bacteria and injecting it to a new one (Levy, 1998). 


\section{Antimicrobial resistance in aquaculture}

In aquaculture, antibiotics are used for the treatment of various infectious diseases. Apart from treatment antibiotics are also used as prophylactic measures and as growth promoter. During administration of antibiotics several factors need to be considered such as safety of the target animal, safety of the fish product, integrity of the environment and safety of the person administering it (Serrano, 2005). But the unauthorised and unregulated use of antimicrobial agents has led to the development of antimicrobial resistant fish pathogens as well as other aquatic bacteria. The resistance has been observed in a number of bacterial species including Aeromonas hydrophila, Asalmonicida Yersinia ruckeri, Edwardsiella tarda, E. icttaluri, Vibrio anguillarum, V. salmonicida, Photobacterium damselae (De Paola, Peeler and Rodrick 1995). As the time passes the number of resistant bacteria is increasing day by day.

Aeromonas salmonicida, the causative agent of furunculosis disease in fish from cold and temperate areas easily develops resistance against antimicrobials. Recent evidence shows multi resistant strains of $A$. salmonicida from different parts of the country that carry transferable resistant plasmid (Romero et al., 2012). Similar cases of other multi resistant bacterial pathogens have been reported from different countries. Multiresistant strains of Vibrio harveyi resistant to chloramphenicol, cotrimoxazole, erythromycin and streptomycin caused mass mortality in Penaeusmonodon larvae as reported by Karunasagar et al., (1994). From these pathogens, the resistance genes can reach the human pathogens either directly or indirectly. The indirect means of dissemination is through horizontal gene transfer for example, transfer of resistance genes from Aeromonas species to Escherichia coli. Direct transfer of resistance genes is through certain bacteria which are common pathogens of aquatic animals as well as human e.g Vibrio species (Heuer et al., 2009). Due to the emergence of resistant bacteria antibiotics have become less effective in controlling infectious diseases. Only a few antimicrobial drugs have been approved by the U.S. Food and Drug Administration (USFDA) for use in aquaculture (Table 1).

The consequences of antimicrobial resistance in bacteria that infect human are- increased number of infections, increased frequency of treatment failures and increased severity of infection (Kruse and Sørum1994). Apart from the human health risk from antimicrobial resistant bacteria the residues of antimicrobials also possess a threat to human health causing allergy, toxicity etc. Some of the antibiotics can accumulate in the flesh of shrimp and the concentration gradually increases with the subsequent use of antibiotics. The antibiotic residues represents potential health hazard and also affects the trade prospects. Therefore, the shrimp health management should focus mainly on disease prevention rather than disease control. Keeping these points in view coastal aquaculture authority (CAA) has banned 20 antibiotics from using in shrimp aquaculture. Avoiding or reducing the use of antimicrobial agents will also improve the environmental integrity and reduce cost of farm management (Table 2).

There are so many pros and cons of using antibiotics but major issues lies with the indiscriminate use. We need to find other safer ways of combating fish diseases. There are several alternative methods which can be used:

Probiotics, prebiotics and synbiotics

Immunostimulants

Bacteriophage therapy

Vaccine

RNA interference

Quorum sensing inhibition 


\section{Probiotics, prebiotics and synbiotics}

Because of the problems lies with the antibiotic use and numerous beneficial effect of probiotics now there is huge increase in the research finding the best and useful probiotics for the use in the aquaculture. A variety of feed additives, including probiotics and prebiotics having beneficial effects to the host was used in aquaculture as prophylactic measure to combat diseases, they are also beneficial as supplements, to improve growth increasing the size and weight gain, and in some cases, act as an alternative antimicrobial compounds (Irianto and Austin, 2002) as well as to stimulate immunity response of the host. Probiotics are the live microbial feed additives that modulate gastrointestinal microbial communities of the host whereas Prebiotics are non-digestible forage additives stimulate the activity or abundance of beneficial gastrointestinal bacteria. Both of these have received widespread attention, showing the improved production, health and disease resistance of aquatic animals (Dimitroglou et al., 2011). When probiotics and prebiotics are used together to an animal so that the probiotic bacteria can grow easily with the help of the probiotics, this system known as the synbiotic.

Probiotics interact with the immune cells such as mononuclear phagocytes (monocytes, macrophages) and polymorphonuclear leukocytes (neutrophils), natural killer (NK) cells, to enhance innate immune responses. Some probiotics can increase the number of erythrocytes, granulocytes, macrophages and lymphocytes in various fishes (Irianto and Austin, 2002; Irianto and Austin, 2003; Kim et al., 2006; Kumar et al., 2008; Nayak et al., 2007). There is report of increase in different innate immune system upon administration/intake of probiotics i.e. In tilapia (Oreochromis niloticus) a two weeks feeding of Lactobacillus rhamnosus significantly stimulates phagocytosis (Pirarat et al., 2006), Stimulation of lysozyme activity in rainbow trout was observed after two weeks feeding with Kocuria sp. SM1 (Sharifuzzaman and Austin, 2009) and Carnobacterium divergens B33 (Sakai et al., 1995), Probiotics such as L. rhamnosus, E. faecium and $B$. subtilis are found to up regulate the proinflammatory cytokines such as IL-1b1 and TGF $\mathrm{b}$ in the spleen and head kidney of the $O$. mykiss (Panigrahi et al., 2007), Sharifuzzaman and Austin(2009) also reported significantly higher anti-protease activity in $O$. mykiss within two weeks of the completion of probiotic species Kocuria. There are numerous numbers of prebiotics are available for the use and they are broadly classified into two categories i.e. oligosaccharides and polysaccharides. The immunomodulatory activity of prebiotics is mediated through direct interactions with their receptors (pattern recognition receptors; PRR), such as b-glucan receptors and dectin-1 receptors that are expressed on macrophages (Brown et al., 2002). This ligand receptor interaction activates signal transduction molecules, such as NF-kB, that stimulate immune cells (Yadav et al., 2002). Also the prebiotics helps by giving direct nutrition to the probiotic bacteria's. Some of the examples for the oligosaccharides are Fructooligosaccharides (FOS), Mannan oligosaccharide (MOS), Immunogen ${ }^{\circledR} \quad($ a commercial product containing two prebiotics, MOS and bglucan), Galactooligosaccharide (GOS), Arabinoxylan-oligosaccharide (AXOS) etc. Examples of polysaccharides are Inulin, bglucan, chitin/chitosan etc.

\section{Immunostimulants}

Immunostimulants comprise a group of biological and synthetic compounds that enhance the nonspecific cellular and humoraldefence mechanism (Maqsood et al., 2011). Immunustimulants mainly activates the white blood cells which plays major role in the 
fish defence mechanism. It may be chemical, drug or naturally occurring compound that elevates the nonspecific defence mechanisms or the specific immune response of the host and may be given alone to activate nonspecific defence mechanisms as well as increasing a specific immune response. Such substances may also, but not necessarily, render animals more resistant to infectious diseases and reduce the risk of disease outbreaks if administrated prior to situations known to result in stress and impaired general performance (e.g. handling, change of temperature and bad environmental condition, weaning of larvae to artificial feeds) or prior to expected increase in exposure to pathogenic microorganisms and parasites (e.g. spring and autumn blooms in the marine environment, high stocking density). In addition, aquaculture may benefit from the use of such immune-stimulants when they are used prior to, and during, developmental phases when the organisms are particularly susceptible to infectious agents (such as fry and fingerling for fishes and larval stages for shrimps or prawns) (Raa, 1996).

The chemical nature nature of different immunostimulant available are mentioned (Raa, 1996). Structural elements of bacteria (lipopolysaccharides (LPS), lipopeptides, capsular glycoproteins and muramylpeptides). Various $\beta$-1,3-glucan products from bacteria (Curdlan) and mycelial fungi (Krestin, Lentinan, Schizophyllan, Scleroglucan, SSG, VitaStim)

$\beta$-1,3/1,6-glucans from the cell wall of baker's yeast (MacroGard, Betafectin)

Complex carbohydrate structures (glycans) from various biological sources including seaweed Peptides present in extracts of certain animals or made by enzymatic hydrolysis of fish protein Nucleotides, and Synthetic products (Bestatin, muramylpeptides, FK-156, FK-565, Levamisole).
Immunostimulants gives so many health benefits like it reduces the fish mortality due to the opportunistic pathogens, prevents different bacterial, viral or parasitic diseases, it enhances the diseases resistance of the young fishes by elevating the non-specific immune system and it can also excel the efficacy of other antimicrobial substances i.e. vaccines. Some examples of efficacy of immunostimulants with injection of $b-1,3 / 1,6$ glucan into fish produces very effective resistance to several bacterial diseases (Robertsen et al., 1990), addition of levamisole $\mathrm{HCl}$ to the diet of Oreochromis niloticus significantly enhanced both cellular and humoral innate immune responses and increased resistance to A. hydrophila infection although they had a little growth promoting activity.

While addition of vitamins $\mathrm{C}$ and $\mathrm{E}$ to Oreochromis niloticus higher than the requirements needed for growth lead to maximum growth compared to levamisole but little enhancement of the immune response as well as resistance to $A$. hydrophila infection (Abdelkhalek et al., 2008). $\beta-1,3 / 1,6-G l u c a n s$ have proved to enhance the biological activity of shrimp hemocytes and to improve growth, survival rate and feed conversion efficacy under experimental conditions (Sung et al., 1994; Song and Hsieh, 1994; Sung et al., 1996).

\section{Bacteriophage therapy}

Considering the negative impact of antibiotics and other chemotherapeutants, biological control of pathogens would be a very useful strategy to combat diseases (mainly bacterial diseases). Historically, they were discovered by Twort (1915) and Dâ€TM Herelle (1917) in the preantibiotic era. Now it has been proved that phage therapy decline the bacterial population below threshold number to a level where the host defence can take care of remaining bacteria. There are two types of 
bacteriophage reproduction occurs in the bacteriophages: (1) Lytic and (2) Lysogenic, in lytic cycle the virus attaches to a host cell and injects its nucleic acid into the cell, directing the host to produce numerous offsprings. These are then released by bursting of the cell, again enters to other cells and the cycle continues.

In lysogenic cycle nucleic acid of the virus becomes part of the host genome and reproduces genetic material in the host cell using the host machinery. In general, the replication of phage in the bacterial cell occurs in five steps: adsorption, penetration of genetic material, replication, maturation and lysis.

Lysogenic bacteriophages incorporate into the genome of the bacterium rather than being lytic. These lysogenic phages are poor candidates for therapy as they do not provide the rapid growth in phage numbers unlike lytic phages. Therefore, lytic phages are good candidate for therapeutic as well as prophylactic use against pathogenic bacterial fish diseases. During the lytic life cycle the number of phages released (burst size) after lysis varies from 50-409 new phage particles (Yang et al., 2010).

Phage control of the disease caused by Pseudomonas plecoglossicida in Plecoglossus altivelis was demonstrated by Park et al., 2000. Park and Nakai (2003), demonstrated the efficacy of Bacteriophage control of Pseudomonas plecoglossicida infection in ayu (Plecoglossus altivelis). Karunasagar et al., 2005 showed the efficacy of bacteriophages to control luminous bacterial disease in shrimp hatcheries by reducing the number of $V$. harveyi counts in water and in larvae and tremendously improved larval survival. A double stranded DNA bacteriophage of Vibrio harveyi was isolated from shrimp farm water which shown efficacy of reducing the luminous bacterial disease to great extent (Vinod et al., 2006). Protective effect (100\% survival). After $6 \mathrm{~h}$ of phage treatment host bacterium concentration reduced (less than 10$3 \mathrm{cfu} \mathrm{ml}^{-1}$ ) in the sera, gill, liver and kidney against Flavobacterium columnare in Clarius batracus (Prasad et al., 2011).

Phage therapy against vibriosis shows good result with elimination of the disease but when the disease is in advanced stage efficacy of phage reduces (Diaz and Morales, 2013). Bacteriophages can be administered to the fishes by different routes i.e. through water bath, oral, injection etc. Various researchers found that no phage neutralizing antibodies were found in phage treated fish (Park and Nakai, 2003). This demonstrate the potential of specific phages to reduce bacterial diseases, with a resulting no negative effect on fish body. There is the need for further investigations of the possibilities in using phages as an alternative to antibiotic treatment of different fish diseases in aquaculture.

\section{Vaccine}

Prevention and control of fish diseases in Aquaculture is a high priority in aquaculture industry. Unlike treating human or other animal diseases, few drugs are available for controlling diseases in fish. Therefore, Control of different diseases in aquaculture and fish farms relies on a combination of good management practices and use of the few approved and commercially available drugs and vaccines for prevention of infections. The immune system is to protect the fish from bacteria, virus, or any foreign antigen (protein). 
Table.1 Drugs approved by USFDA for use in aquaculture

\begin{tabular}{|l|l|l|}
\hline Immersion & Injection & Medicated Articles/Feeds \\
\hline Chloramine-T & Chorionic gonadotropin & $\begin{array}{l}\text { Florfenicol } \\
\text { Oxytetracycline dihydrate }\end{array}$ \\
\hline Formalin & & Sulfadimethoxine/ormetoprim \\
\hline Hydrogen peroxide & & \\
\hline Oxytetracycline hydrochloride & & \\
\hline Tricainemethanesulfonate & & \\
\hline
\end{tabular}

Table.2 List of antibiotics and other pharmacologically active substances banned for using in shrimp aquaculture by CAA

\begin{tabular}{|r|l|}
\hline SI. No. & \multicolumn{1}{|c|}{ Antibiotics and other Pharmacologically Active Substances } \\
\hline 1. & Chloramphenicol \\
\hline 2. & $\begin{array}{l}\text { Nitrofurans including: Furaltadone, Furazolidone, Furylfuramide, Nifuratel, } \\
\text { Nifuroxime, Nifurprazine, Nitrofurantoin, Nitrofurazone }\end{array}$ \\
\hline 3. & Neomycin \\
\hline 4. & Nalidixic acid \\
\hline 5. & Sulphamethoxazole \\
\hline 6. & Aristolochiaspp and preparations thereof \\
\hline 7. & Chloroform \\
\hline 8. & Chlorpromazine \\
\hline 9. & Colchicine \\
\hline 10. & Dapsone \\
\hline 11. & Dimetridazole \\
\hline 12. & Metronidazole \\
\hline 13. & Ronidazole \\
\hline 14. & Ipronidazole \\
\hline 15. & Other nitroimidazoles \\
\hline 16. & Clenbuterol \\
\hline 17. & Diethylstilbestrol (DES) \\
\hline 18. & $\begin{array}{l}\text { Sulfonamide drugs (except approved Sulfadimethoxine, Sulfabromomethazine and } \\
\text { Sulfaethoxypyridazine) }\end{array}$ \\
\hline 19. & Fluroquinolones \\
\hline 20. & Glycopeptides \\
\hline
\end{tabular}

Therefore, before attempting any vaccination strategy, it is important to determine when the immune system and immune cells are both morphologically and functionally mature (Toranzo et al., 2009). Fish immunology has a more recent history than human and veterinary immunology but the techniques used are similar. However, methods of administering vaccines to fish differ and are dependent upon species, pathogen, temperature and environment (Anderson, 1974). There are different types of vaccines available for treating fishes i.e. 1. Killed vaccine 2. Live attenuated vaccine 3 . Recombinant vaccine. Under recombinant vaccine there are so many types of vaccine 
i.e. a. recombinant subunit vaccine, b. recombinant attenuated vaccine, and c. recombinant vectored vaccine available. The ideal vaccine formulation for the fisheries sector is polyvalent vaccine, which protects simultaneously against the majority of the fish pathogens to which a particular fish species is susceptible (Busch, 1997). Depending upon fish species and temperature, vaccination must be performed within a certain minimum period before the risk of their exposure to pathogens. In addition to temperature, stress caused by environments, crowding, handling and transport, can induce immune suppression and be a limiting factors for vaccine efficacy (Sommerset et al., 2005). Fish are commonly immunized by three procedures: intraperitoneal injection (ip), immersion in a diluted vaccine solution (short or long bath), or oral administration of the vaccine (Komar et al., 2004). All this different mode of vaccine delivery methods have its own pros and cons most effective method is vaccine delivery by injection but most widely used and practical vaccine delivery method in fisheries sector is immersion, oral is also a good option for vaccine delivery but intestinal degradation of vaccine and feed acceptability is big concern.

First commercially available fish bacterial vaccine were against enteric red mouth disease causes by Yersinia ruckeri and vibriosis commercialised in the USA in the late 1970s (Evelyn et al., 1997). The first viral vaccine for fish was produced by a Czechoslovakian company (Bioveta) in 1982. The vaccine was against a carp rhabdovirus, causing spring viremia of carp (SVC) in salmonids and was based on two inactivated strains of SVC virus emulsified in oil and administered by injection. Till date no commercial vaccine against parasitic diseases are available but so many experimental vaccines are there. Currently, there are only 14 licensed fish vaccines in U.S., including 11 killed bacterial, 1 killed viral, and 2 live attenuated bacterial prophylactics. Vaccination in the fishes stars with mainly killed vaccines and attenuated vaccine but both of this type of vaccines are having disadvantages like poor immunogenic and pathogenicity reversion in the case of attenuated vaccines. So new generation vaccines like recombinant vaccines are coming up which are showing good results in experimental conditions and believed to be the next generation vaccine. Most of these recombinant vaccines are based on only the virulent gene or the protein expressed. Some of the recombinant vaccines which are licensed in different countries are infectious hematopoietic necrosis virus (IHNV) form recombinant $\mathrm{G}$ protein, licensed in Canada; spring viremia of carp virus (SVCV) from recombinant $\mathrm{G}$ protein in baculovirus expression system, licensed in Belgium; infectious salmon anemia virus (ISAV) from recombinant hemagglutinin esterase protein, licensed in Chile; infectious pancreatic necrosis virus (IPNV) from VP2 and VP3 capsid proteins and VP2 protein (Trivalent SRS/ IPNV/Vibrio) licensed in Canada and Chile, respectively (Dhar et al., 2014). Till date most of the vaccine that have been commercialized is for the cold water high value fishes very few vaccines are available commercially for tropical fishes i.e. vaccine against Grass carp reovirus in China and KHV in Israel (Tian et al., 2013).

Aquaculture industry is rapidly growing and vaccination for prevention of fish diseases will play a major role in the coming future. Till date only some vaccines are available that to for some important bacterial and viral diseases, till date no commercial fungal or parasitic vaccines are available. There are so many hurdles in vaccine development for the aquatic environment such as high pathogenic variation, cost effectiveness of the vaccine, lack of knowledge about fish immune system, 
problem related to vaccine administration etc. But laboratory experiments are showing hope for the effective vaccine development which may in the near future.

\section{RNA interference}

The phenomenon of RNA interference (RNAi) was first observed in the late 1980s and has since evolved into a powerful laboratory technique for potent and specific gene silencing (Caplen et al., 2004, Leung and Whittaker 2005). The presence of a double-stranded RNA (dsRNA) in eukaryotic cells triggers this post-transcriptional genesilencing mechanism, leading to a sequencespecific degradation of the target mRNA (Krishnan et al., 2009). Turning off the expression of a gene is possible at two levels 1. Transcriptional gene silencing and 2. Post transcriptional gene silencing. Among the many applications of RNAi technology therapeutic silencing of virulent genes has received maximum attention. There are 3 broad stages in developing an RNAi based therapy: design, synthesis and delivery. In each of these broad stages, one has to consider a number of specific details in order to develop an efficient RNAi-based therapy (Krishnan et al., 2009). The posttranscriptional activity of the RNAi machinery to degrade cytoplasmic RNA in a sequence-specific manner is the key to its antiviral function in invertebrates. For effective RNAi treatment identification of target gene is very much important. After identification of the gene of interest we can go for different strategies of RNAi treatment i.e. 1. siRNA - These are designed after the natural Dicer cleavage products. The in vitro synthesized siRNAs are 21 nucleotide long with 2neocleotide 3' overhangs (Elbashir et al., 2001). The key advantage with these molecules is that they avoid overloading of cellular elements and result in fewer nonspecific side effects, 2. shRNA -shRNA designed after pre-miRNAs having a small apical loop and 3' UU overhang and are designed as plasmids that express anti-viral short hairpin RNA from a pol III promoter (Paddison et al., 2002). shRNAs are translocated from the nucleus to the cytoplasm with the help of Exportin-5 and further processed in the cytoplasm by cellular Dicer to form functional siRNAs. They can be used for long-term silencing, inducible expression and tissue specific delivery, 3. lhRNA - These are similar to shRNAs except that they are larger and induce RNAi by intracellular expression of long hairpin RNAs. 4. miRNA - They constitute the second generation of RNAi-mediating constructs based on the structure of existing miRNA (Stegmeier et al., 2005). This RNAi technology is getting very much focus in the treatment of viral diseases and mainly the shrimp diseases as we know that shrimps don't contains adaptive immunity so vaccination to the shrimps is not possible. RNAi based vaccines experimentally show good results in controlling diseases like WSSV, YHV, IHHNV etc. So more research is needed before commercialization of the technology and RNAi technology is having a very promising future in the field of therapy.

\section{Quorum sensing inhibition}

Quorum sensing is a mechanism in which bacterial population as a whole coordinate's gene expressions in response to their population density by producing, releasing and recognizing small signal molecules called auto inducers (Suga and Smith 2003, Defoirdt et al., 2004). Quorum sensing regulates various phenotypes such as biofilm formation (Merritt et al., 2003, Parsek and Greenberg 2005), bioluminescence (Waters and Bassler 2005, Bodman et al., 2008), virulence factors (Mellbyeand Schuster, 2011) and swarming (Shrout et al., 2006) which have been shown its contribution towards bacterial virulence. 
Since virulence traits of bacteria are controlled by quorum sensing, disruption of quorum sensing has been suggested as a new treatment strategy to control pathogenic bacteria (Finch et al., 1998) in the field of aquaculture and animal husbandry. Quorum quenching (QQ), the disruption of Quorum sensing, can be performed by small antagonists molecules (Givskovm et al., 1996) or signal degrading enzymes (Roy et al., 2011). Many microorganisms can produce enzymes which can degrade N-Acyl homoserinelactones (AHLs) which plays major role in the quorum sensing (Christiaen et al., 2011). The Quorum quenching enzymes produced by microorganisms were classified into three major types according to their enzymatic mechanisms: AHL lactonase (lactone hydrolysis), AHL acylase (amidohydrolysis) and AHL oxidase and reductase (oxidoreduction). These enzymes can degrade AHLs, and as a results of this they can prevent pathogenic bacteria from producing virulence factors, forming biofilms thus reducing virulence. So the Quorum quenching microorganisms can be used as potential quenchers of quorum-sensingregulated functions in pathogenic bacteria (Kalia, 2013). This method of bacterial inhibition can be very effective for the aquaculture industry. Cam et al., (2009a) reported isolation of two different mixtures of AHL degrading enrichment cultures (ECs) from European sea bass [Dicentrarchus labrax, EC5(D)] and from Asian sea bass [Lates calcarifer, EC5(L)]. These novel ECs can act as quorum quencher and as probiotics in aquaculture system (Cam 2009b). Nhan et al., (2010) investigated the effect of EC5(D) and $\mathrm{EC5}(\mathrm{L})$ on Macrobrachium rosenbergii larval performance against vibrio harveyi, which shows encouraging results. In-vitro quenching of Edward seillatarda AHLs by Tenacibaculum sp. strain 20J (Romero et al., 2014). Still this Quorum quenching of bacteria is in experimental phage but if we can use it in a holistic approach then it can be good candidate treatment method in the aquaculture industry.

\section{References}

Abdelkhalek, N. K., Viola, H. Z., and Yousef, M. A. A. 2008. Effect of some immunostimulants on health status and disease resistance of Nile tilapia (Oreochromis niloticus). In Proceedings of the Eighth International Symposium on Tilapia in Aquaculture (ISTA 8), Elghobashy H, Fitzsimmons K, Diab AS, eds., Cairo, Egypt (pp. 10-1088).

Bradford, P. A. 2001. Extended-spectrum $\beta$ lactamases in the 21st century: characterization, epidemiology, and detection of this important resistance threat. Clinical microbiology reviews, 14: 933951.

Brown, G. D., Taylor, P. R., Reid, D. M., Willment, J. A., Williams, D. L., Martinez Pomares, L., and Gordon, S. 2002. Dectin-1 is a major $\beta$-glucan receptor on macrophages. The Journal of experimental medicine, 196(3), 407-412.

Busch, R. A. 1996. Polyvalent vaccines in fish: the interactive effects of multiple antigens. Developments in biological standardization, 90, 245-256.

Cam, D.T.V., 2009b. The use of homoserine lactone-degrading and poly- $\mathrm{b}-$ hydroxybutyrate-accumulating bacteria in crustacean and fish larviculture. $\mathrm{PhD}$ Thesis, Gent University, Belgium. pp. 290.

Cam, D.T.V., Hao, N.V., Dierckens, K., Defoirdt, T., Boon, N., Sorgeloos, P. and Bossier, P. 2009a. Novel approach of using homoserine lactone degrading and poly-bhydroxybutyrate accumulating bacteria to protect Artemia from the pathogenic effects of Vibrio harveyi. Aquaculture 291, 23-30.

Caplen, N. J. 2004. Gene therapy progress and prospects. Downregulating gene expression: the impact of RNA interference. Gene therapy, 11(16), 12411248.

Christiaen, S. E., Brackman, G., Nelis, H. J., and Coenye, T. 2011. Isolation and 
identification of quorum quenching bacteria from environmental samples. Journal of microbiological methods, 87(2), 213-219.

Davies, J. 1994. Inactivation of antibiotics and the dissemination of resistance genes. Science, 264: 375-382.

Defoirdt, T., Boon, N., Bossier, P., and Verstraete, W. 2004. Disruption of bacterial quorum sensing: an unexplored strategy to fight infections in aquaculture. Aquaculture, 240(1), 69-88.

Depaola, A., Peeler, J. T. and Rodrick, G. E. 1995. Effect of oxytetracycline-medicated feed on antibiotic resistance of gramnegative bacteria in catfish ponds. Applied and environmental microbiology, 61: 23352340.

Dhar, A. K., Manna, S. K., and Allnutt, F. T. 2014. Viral vaccines for farmed finfish. Virus Disease, 25(1), 1-17.

Dimitroglou, A., Merrifield, D. L., Carnevali, O., Picchietti, S., Avella, M., Daniels, C, D. Güroy and Davies, S. J. 2011. Microbial manipulations to improve fish health and production-a Mediterranean perspective. Fish and Shellfish Immunology, 30(1), 116.

Drapeau, C., Grilli, E. and Petrosillo, N. 2010. Rifampicin combined regimens for Gramnegative infections: data from the literature. International journal of antimicrobial agents, 35: 39-44.

Elbashir, S. M., Harborth, J., Lendeckel, W., Yalcin, A., Weber, K., and Tuschl, T. 2001. Duplexes of 21-nucleotide RNAs mediate RNA interference in cultured mammalian cells. Nature, 411(6836), 494-498.

Evelyn, T. P. 1996.A historical review of fish vaccinology. Developments in biological standardization, 90, 3-12.

Fabrega, A., Du Merle, L., Le Bouguenec, C., de Anta, M. T. J. and Vila, J. 2009. Repression of invasion genes and decreased invasion in a high-level fluoroquinolone-resistant Salmonella typhimurium mutant. PloS one, 4: e8029.

Finch, R. G., Pritchard, D. I., Bycroft, B. W., Williams, P., and Stewart, G. S. A. B. 1998. Leading articles-Quorum sensing: A novel target for anti-infective therapy. Journal of
Antimicrobial Chemotherapy, 42(5), 569571.

Fisher, J. F., Meroueh, S. O. and Mobashery, S. 2005. Bacterial resistance to $\beta$-lactam antibiotics: compelling opportunism, compelling opportunity. Chemical reviews, 105: 395-424.

Givskov, M., de Nys, R., Manefield, M., Gram, L., Maximilien, R. I. A., Eberl, L. E. O., and Kjelleberg, S. 1996. Eukaryotic interference with homoserine lactonemediated prokaryotic signalling. Journal of bacteriology, 178(22), 6618-6622.

Heuer, O. E., Kruse, H., Grave, K., Collignon, P., Karunasagar, I. and Angulo, F. J. 2009. Human health consequences of use of antimicrobial agents in aquaculture. Clinical Infectious Diseases, 49: 12481253.

Higgins, C. F. 2007. Multiple molecular mechanisms for multidrug resistance transporters. Nature, 446: 749-757.

Irianto, A., and Austin, B. 2002. Probiotics in aquaculture. Journal of fish diseases, 25(11), 633-642.

Kalia, V. C. 2013. Quorum sensing inhibitors: an overview. Biotechnology advances, 31(2), 224-245.

Karunasagar, I., Pai, R., Malathi, G. and Karunasagar, I. 1994. Mass mortality of Penaeusmonodon larvae due to antibioticresistant Vibrio harveyi infection. Aquaculture, 128: 203-209.

Karunasagar. I., Vinod, M. G., Kennedy, B., Vijay, A. T. N. U. R., Deepanjali, A., Umesha, K. R., and Karunasagar, I. 2005. Biocontrol of bacterial pathogens in aquaculture with emphasis on phage therapy. Diseases in Asian Aquaculture V. Fish Health Section, Asian Fisheries Society, Manila, 535-542.

Kim, D. H., and Austin, B. 2006. Cytokine expression in leucocytes and gut cells of rainbow trout, Oncorhynchus mykiss Walbaum, induced by probiotics. Veterinary immunology and immunopathology, 114(3), 297-304.

Kitaoka, M., Miyata, S. T., Unterweger, D. and Pukatzki, S. 2011. Antibiotic resistance mechanisms of Vibrio cholerae. Journal of medical microbiology, 60: 397-407. 
Komar, C., Enright, W. J., Grisez, L., and Tan, Z. 2004. Understanding fish vaccination. Aqua Culture Asia Pacific Magazine, 27-9.

Krämer, R. 1994. Functional principles of solute transport systems: concepts and perspectives. Biochimicaet Biophysica Acta (BBA)-Bioenergetics, 1185: 1-34.

Kruse, H. and Sørum, H. 1994. Transfer of multiple drug resistance plasmids between bacteria of diverse origins in natural microenvironments. Applied and environmental microbiology, 60: 40154021.

Kumar, A. and Schweizer, H. P. 2005. Bacterial resistance to antibiotics: active efflux and reduced uptake. Advanced drug delivery reviews, 57: 1486-1513.

Kumar, R., Mukherjee, S. C., Ranjan, R., \&Nayak, S. K. 2008. Enhanced innate immune parameters in Labeorohita (Ham.) following oral administration of Bacillus subtilis. Fish and shellfish immunology, 24(2), 168-172.

Kumar, S. and Varela, M. F. 2013. Molecular mechanisms of bacterial resistance to antimicrobial agents. chemotherapy, 14: 18.

Landers, T. F., Cohen, B., Wittum, T. E. and Larson, E. L. 2012. A review of antibiotic use in food animals: perspective, policy, and potential. Public health reports: 4-22.

Le, T. X. and Munekage, Y. 2004. Residues of selected antibiotics in water and mud from shrimp ponds in mangrove areas in Viet Nam. Marine pollution bulletin, 49: 922929.

Leung, R. K., and Whittaker, P. A. 2005. RNA interference: from gene silencing to genespecific therapeutics. Pharmacology and therapeutics, 107(2), 222-239.

Levy, S. 2002. Active efflux, a common mechanism for biocide and antibiotic resistance. Journal of applied microbiology, 92.

Levy, S. B. 1998. The challenge of antibiotic resistance. Scientific American, 278:46-53.

Levy, S. B. 2005. Antibiotic resistance- the problem intensifies. Advanced drug delivery reviews, 57: 1446-1450.

Maqsood S, Prabjeet S, Munir HS, Khusheebee M. 2011. Emerging role of immunostimulants in combating the disease outbreak in aquaculture. International Journal of Aquatic Research. 3, 147-163.

Mellbye, B., and Schuster, M. 2011. The sociomicrobiology of antivirulence drug resistance: a proof of concept. MBio, 2(5), e00131-11.

Merritt, J., Qi, F., Goodman, S. D., Anderson, M. H., and Shi, W. 2003. Mutation of luxS affects biofilm formation in Streptococcus mutans. Infection and Immunity, 71(4), 1972-1979.

Monack, D. M. 2012. Salmonella persistence and transmission strategies. Current opinion in microbiology, 15: 100-107.

Morris, A., Kellner, J. D. and Low, D. E. 1998. The superbugs: evolution, dissemination and fitness. Current opinion in microbiology, 1: 524-529.

Murray, P. R., Rosenthal, K. S. and Pfaller, M. A. 2012. Medical Microbiology, Elsevier Health Sciences.

Nayak, S. K., Swain, P., and Mukherjee, S. C. 2007. Effect of dietary supplementation of probiotic and vitamin $\mathrm{C}$ on the immune response of Indian major carp, Labeorohita (Ham.).Fish and shellfish immunology, 23(4), 892-896.

Neu, H. C. and Gootz, T. D. 1996. Antimicrobial chemotherapy. Medical Microbiology. 4th edition

Nhan, D. T., Cam, D. T. V., Wille, M., Defoirdt, T., Bossier, P., and Sorgeloos, P. 2010. Quorum quenching bacteria protect Macrobrachium rosenbergii larvae from Vibrio harveyi infection. Journal of applied microbiology, 109(3), 1007-1016.

Paddison, P. J., Caudy, A. A., Bernstein, E., Hannon, G. J., and Conklin, D. S. 2002. Short hairpin RNAs (shRNAs) induce sequence-specific silencing in mammalian cells. Genes\& development, 16(8), 948958.

Pagès, J.-M., James, C. E. and Winterhalter, M. 2008. The porin and the permeating antibiotic: a selective diffusion barrier in Gram-negative bacteria. Nature Reviews Microbiology, 6: 893-903.

Panigrahi, A., Kiron, V., Satoh, S., Hirono, I., Kobayashi, T., Sugita, H., and Aoki, T. 2007. Immune modulation and expression of cytokine genes in rainbow trout 
Oncorhynchusmykiss upon probiotic feeding. Developmental and Comparative Immunology, 31(4), 372-382.

Park, S. C., and Nakai, T. 2003. Bacteriophage control of Pseudomonas plecoglossicida infection in ayu Plecoglossus altivelis. Diseases of aquatic organisms, 53(1), 3339.

Park, S. C., Shimamura, I., Fukunaga, M., Mori, K. I., and Nakai, T. 2000. Isolation of bacteriophages specific to a fish pathogen, Pseudomonas plecoglossicida, as a candidate for disease control. Applied and environmental microbiology, 66(4), 14161422.

Parsek, M. R., and Greenberg, E. P. 2005. Sociomicrobiology: the connections between quorum sensing and biofilms. Trends in microbiology, 13(1), 27-33.

Philippon, A. 1989. Labia R, Jacoby G. Extendedspectrum 0-lactaniases.Antimicrob Agents Chemother, 33.

Pirarat, N., Kobayashi, T., Katagiri, T., Maita, M., and Endo, M. 2006. Protective effects and mechanisms of a probiotic bacterium Lactobacillus rhamnosus against experimental Edwardsiella tarda infection in tilapia (Oreochromis niloticus).Veterinary immunology and immunopathology, 113(3), 339-347.

Poolman, B. and Konings, W. N. 1993. Secondary solute transport in bacteria. Biochimicaet Biophysica Acta (BBA)-Bioenergetics, 1183: 5-39.

Prasad, Y., Kumar, D., and Sharma, A. K. 2011. Lytic bacteriophages specific to Flavobacterium columnare rescue catfish, Clariasbatrachus (Linn.) from columnaris disease. Journal of environmental Biology 32:161-168.

Raa, J. 2000. The use of immune-stimulants in fish and shellfish feeds. Avances en Nutrición Acuícola V. Memorias del V Simposium Internacional de Nutrición Acuícola, 19(22), 47-56.

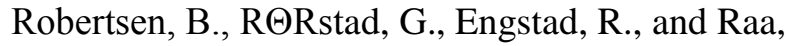
J. 1990. Enhancement of non- specific disease resistance in Atlantic salmon, Salmosalar L., by a glucan from Saccharomyces cerevisiae cell walls. Journal of Fish Diseases, 13(5), 391-400.
Romero, J., Feijoó, C. G. and Navarrete, P. 2012. Antibiotics in aquaculture-use, abuse and alternatives, INTECH Open Access Publisher.

Romero, M., Muras, A., Mayer, C., Buján, N., Magariños, B., and Otero, A. 2014. In vitro quenching of fish pathogen Edwardsiella tarda AHL production using marine bacterium Tenacibaculum sp. strain 20J cell extracts. Diseases of aquatic organisms, 108(3), 217-225.

Roy, V., Adams, B. L., and Bentley, W. E. 2011. Developing next generation antimicrobials by intercepting AI-2 mediated quorum sensing. Enzyme and microbial technology, 49(2), 113-123.

Sakai, M., Yoshida, T., Atsuta, S., and Kobayashi, M. 1995. Enhancement of resistance to vibriosis in rainbow trout, Oncorhynchus mykiss (Walbaum), by oral administration of Clostridium butyricum bacterin. Journal of Fish Diseases, 18(2), 187-190.

Serrano, P.H., 2005. Responsible use of antibiotics in aquaculture. FAO Fisheries Technical Paper. No. 469. FAO, Rome.

Sharifuzzaman, S. M., and Austin, B. 2009. Influence of probiotic feeding duration on disease resistance and immune parameters in rainbow trout. Fish and Shellfish Immunology, 27(3), 440-445.

Shrout, J. D., Chopp, D. L., Just, C. L., Hentzer, M., Givskov, M., and Parsek, M. R. 2006. The impact of quorum sensing and swarming motility on Pseudomonas aeruginosa biofilm formation is nutritionally conditional. Molecular microbiology, 62(5), 1264-1277.

Sommerset, I., Krossøy, B., Biering, E., and Frost, P. 2014. Vaccines for fish in aquaculture. Expert review of vaccines.

Song, Y. L., and Hsieh, Y. T. 1994. Immunostimulation of tiger shrimp (Penaeus monodon) hemocytes for generation of microbicidal substances: analysis of reactive oxygen species. Developmental and Comparative Immunology, 18(3), 201-209.

Spratt, B. G. 1994. Resistance to antibiotics mediated by target alterations. ScienceAAAS-Weekly Paper Edition-including 
Guide to Scientific Information, 264: 388396.

Stegmeier, F., Hu, G., Rickles, R. J., Hannon, G. J., and Elledge, S. J. 2005. A lentiviral microRNA-based system for single-copy polymerase II-regulated RNA interference in mammalian cells. Proceedings of the National Academy of Sciences of the United States of America, 102(37), 1321213217.

Strateva, T. and Yordanov, D. 2009. Pseudomonas aeruginosa-a phenomenon of bacterial resistance. Journal of medical microbiology, 58: 1133-1148.

Suga, H., and Smith, K. M. 2003. Molecular mechanisms of bacterial quorum sensing as a new drug target. Current opinion in chemical biology, 7(5), 586-591.

Sung, H. H., Yang, Y. L., and Song, Y. L. 1996. Enhancement of microbicidal activity in the tiger shrimp Penaeusmonodon via immunostimulation. Journal of Crustacean Biology, 16(2), 278-284.

Sung, HH, Kou, GH, and Song, YL 1994. Vibriosis resistance induced by glucan treatment in tiger shrimp (Penaeus monodon). Fish Disease Research, 29 (1), 11-17.

Tian, Y., Ye, X., Zhang, L., Deng, G., and Bai, Y. 2013. Development of a novel candidate subunit vaccine against Grass carp reovirus Guangdong strain (GCRV-GD108). Fish and shellfish immunology, 35(2), 351-356.

Toranzo, A. E., Romalde, J. L., Magariños, B., and Barja, J. L. 2009. Present and future of aquaculture vaccines against fish bacterial diseases. Options Mediterraneennes, 86, 155-176.

Van Cam, D. T., Van Hao, N., Dierckens, K., Defoirdt, T., Boon, N., Sorgeloos, P., and
Bossier, P. 2009a. Novel approach of using homoserine lactone-degrading and poly- $\beta$ hydroxybutyrate-accumulating bacteria to protect Artemia from the pathogenic effects of Vibrio harveyi. Aquaculture, 291(1), 2330.

Vinod, M. G., Shivu, M. M., Umesha, K. R., Rajeeva, B. C., Krohne, G., Karunasagar, I., and Karunasagar, I. 2006. Isolation of Vibrio harveyi bacteriophage with a potential for biocontrol of luminous vibriosis in hatchery environments. Aquaculture, 255(1), 117-124.

Von Bodman, S. B., Willey, J. M., and Diggle, S. P. 2008. Cell-cell communication in bacteria: united we stand. Journal of bacteriology, 190(13), 4377-4391.

Waters, C. M., and Bassler, B. L. 2005. Quorum sensing: cell-to-cell communication in bacteria. Annual Review for Cell Development Biology. 21, 319-346.

Wright, G. D. 2005. Bacterial resistance to antibiotics: enzymatic degradation and modification. Advanced drug delivery reviews, 57: 1451-1470.

Yadav, M., and Schorey, J. S. 2006. The $\beta$-glucan receptor dectin-1 functions together with TLR 2 to mediate macrophage activation by mycobacteria. Blood, 108(9), 3168-3175.

Yang, H., Liang, L., Lin, S., and Jia, S. 2010. Isolation and characterization of a virulent bacteriophage $\mathrm{AB} 1$ of Acinetobacter baumannii. BMC microbiology, 10(1), 1.

Yang, W., Moore, I. F., Koteva, K. P., Bareich, D. C., Hughes, D. W. and Wright, G. D. 2004. TetX is a flavin-dependent monooxygenase conferring resistance to tetracycline antibiotics. Journal of Biological Chemistry, 279: 52346-52352.

\section{How to cite this article:}

Nilav Aich, Naznin Ahmed and Anirban Paul. 2018. Issues of Antibiotic Resistance in Aquaculture Industry and Its Way Forward. Int.J.Curr.Microbiol.App.Sci. 7(08): 26-41. doi: https://doi.org/10.20546/ijcmas.2018.708.004 